\title{
Psicologia, diferença e epistemologia: percorrendo os (des)caminhos de uma constituição paradoxal
}

Psychology, difference and epistemology: retracing the paths of a paradoxical constitution. Psicología, diferencia y epistemología: recorriendo los (des)caminos de una constitución paradójica

\section{Pablo Severiano Benevides*}

\section{Resumo}

Este trabalho constitui uma tentativa de estabelecer um fio condutor interligando alguns dos principais problemas que assolam o campo da Psicologia: as dificuldades em se erigir como um campo inscrito em uma racionalidade epistêmica ("logia”); a tensão entre as diversas perspectivas teórico-epistemológicas que habitam seu interior, principalmente na circunstância em que recorrem à racionalidade epistemológica para configurarem uma imagem de "Homem"; bem como a cisão, entendida em suas múltiplas formas de aparecimento, entre a atividade teórica e a prática de tal campo. As dificuldades mencionadas serão compreendidas, assim, não como estruturais e definitivas, mas como formas de situar o campo "psi” na tensão entre o espaço do devir, do acontecimento e das multiplicidades que constituem o movimento da diferença e o espaço da epistemologia, caracterizado pelo julgamento e policiamento do pensamento humano, cujo correlato constitui tanto a imagem do pensamento, como o ideal de Homem e de sujeito característicos da Modernidade.

Palavras-chaves: Psicologia. Diferença. Epistemologia.

\begin{abstract}
This presentation tries to establish a link with the main issues that surround the Psychological field: the difficulties in establishing itself as a field entered into an epistemic rationality ("logy"); the tension between the several Theoretical-epistemologically perspective that inhabit its interior, especially in the circumstances in which they avail themselves of the epistemological rationality to configure an image of "Man": as
\end{abstract}

\footnotetext{
Doutor em Educação e mestre em Filosofia e pela Universidade Federal do Ceará, com estágio doutoral no Programa de Pós-Graduação em Educação da Universidade do Estado do Rio de Janeiro (Proped/UERJ); professor adjunto I do Curso de Psicologia (UFC/Sobral) e professor do Programa de Pós-Graduação em Psicologia (UFC/Fortaleza), filiado à linha de pesquisa "Cultura e Subjetividades Contemporâneas"; psicólogo; pesquisador do Laboratório de Estudos Foucaultianos (UFC/UECE) e do Núcleo de Estudos em Filosofia e Infância - NEFI (UERJ). E-mail: pabloseverianobenevides@hotmail.com.
} 
much as the split, known as its multiple shapes, in a theoretical as well as practical sense. The difficulties mentioned will be understood therefore, not as structural and definitive, but as a way to locate the "psy" area which is under pressure of the becoming, the event and its multiplicities that are the movement of the differences and the space of the Epistemology, characterized by trial and policing of human thought, whose correlative constitutes both the Image of Thought, but also as the idea of Man as a subject of the Modernity.

Keywords: Psychology. Difference. Epistemology.

\section{Resumen}

Este trabajo constituye una tentativa de establecer un hilo conductor entre algunos de los principales problemas que asolan el campo de la Psicología: las dificultades para erigirse como un campo inscrito en una racionalidad epistémica ("logía”); la tensión entre las diversas perspectivas teórico-epistemológicas que habitan su interior, principalmente en las circunstancias en las que se recurre a la racionalidad epistemológica para configurar una imagen de "Hombre"; así como la cisión, entendida en sus múltiples formas de surgimiento entre la actividad teórica y la práctica de tal campo. Las dificultades mencionadas serán comprendidas, de este modo, no como estructurales y definitivas, sino como formas de situar el campo "psi" en la tensión entre el espacio del devenir, del acontecimiento y de las multiplicidades que constituyen el movimiento de la diferencia y el espacio de la epistemología, caracterizado por el juicio y la vigilancia del pensamiento humano, cuyo correlato constituye tanto la Imagen del pensamiento, como el ideal de Hombre y de sujeto característicos de la Modernidad.

Palabras clave: Psicología. Diferencia. Epistemología.

\section{Introdução}

Este trabalho pretende articular uma reflexão sobre os movimentos de constituição do campo psicológico com base em um conjunto de tensões entre a dimensão epistemológica por ele almejada e a dimensão relativa à diferença, ao devir e às multiplicidades insubordináveis à racionalidade epistêmica. Baseados nisso, configuraremos os referenciais teóricos que situam a perspectiva a partir da qual trabalharemos as possíveis relações entre Psicologia, epistemologia e diferença. Essas relações serão objeto de nosso interesse especificamente nas circunstâncias em que definem os contornos 
e constituem os paradoxos inerentes ao agenciamento do campo "psi" com a racionalidade epistêmica "logia", agenciamento este que pretende desvencilhar-se de sua tensão constitutiva a partir da formação de um campo de (não) saber chamado de "Psicologia".

A tensão constitutiva desse campo é, por vezes, descrita como um paradoxo, como um mal-entendido, ou como um desencaixe entre tudo aquilo que é próprio do campo da "logia" (racionalidade, epistemologia, conhecimento e controle) e os elementos que desse campo são expulsos e expurgados, formando o campo "psi" (a ilusão, o erro, a loucura, o delírio, o esquecimento, as paixões). O momento de estabilização consistirá, portanto, em um movimento de segunda ordem, por parte da Psicologia, no sentido de se apropriar de tudo aquilo que constitui um desvio em relação à verdade e ao conhecimento. Desse modo, o esforço de segunda ordem da Psicologia (a saber, a tentativa de captura e neutralização daquilo que inicialmente a constitui) poderá, ainda, esclarecer a origem de uma série de desencontros que ganham corpo e fazem problema no próprio domínio que consideramos como sendo o campo "prático" da atuação profissional do psicólogo. Isso porque há uma importante relação, que deverá ser mais bem esclarecida, entre o desencaixe acima referido e a constante tensão (que aparece constantemente sob a forma da oposição binária "teoria" e "prática") entre a atitude epistemológica, teórica e crítica (muitas vezes tidas como equivalentes nesse campo) por parte intelectual do pesquisador do campo da Psicologia e a atitude empírica, prática e profissional do psicólogo (usualmente considerada como a verdadeira "realidade"). Assim, longe de tentarmos suturar essa tensão com aforismos que proclamam, independentemente do funcionamento real dos discursos e práticas psi, uma harmonização, integração ou complementação entre "teoria" e "prática" ou entre Psicologia e epistemologia, este trabalho pretende lançar luzes para traçarmos uma genealogia dessas cisões, dessas tensões e desses desencontros constitutivos do e coincidentes com o advento do campo da Psicologia.

As problemáticas acima mencionadas serão, neste trabalho, perspectivadas pelos escritos de Luís Cláudio Figueiredo, em especial, pelas obras Matrizes do pensamento psicológico (2002), A invenção do psicológico (2007) e Revisitando as psicologias (1996). Realizaremos, contudo, um pequeno deslocamento em relação à leitura de Luís Cláudio Figueiredo: em vez de tomarmos o pensamento de Martin Heidegger para nos aproximarmos dessa dimensão referente à novidade, à experimentação, à alteridade e ao devir que escapam às grades da epistemologia como instância jurídica, crítica e reguladora do pensamento, perspectivaremos essa compreensão a partir do campo teóricopolítico das filosofias da diferença, em especial pelo pensamento de Michel 
Foucault, mas também de Friedrich Nietzsche e Gilles Deleuze. Desse modo, será por essa via que nos afiliaremos às multiplicidades, aos movimentos, às rupturas, às resistências, aos acontecimentos e aos devires (em uma palavra, à diferença) que escapam teórica, política e esteticamente da fixidez imposta pela atitude policialesca da(s) epistemologia(s), mas também da(s) Psicologia(s), nas circunstâncias em que realiza $(\mathrm{m})$ um esforço de segunda ordem para domar(em), domesticar(em) e docilizar(em) a diferença constitutiva de seu campo.

Desse modo, para melhor observarmos o ponto de vista que queremos nos situar neste trabalho, configuraremos três movimentos de constituição do campo psicológico, levando em conta sua atitude diante da diferença contra a epistemologia, da diferença entre suas formas de ascender à epistemologia e da diferença em relação à epistemologia. Assim, organizaremos essa exposição em três tópicos, referentes à constituição do campo "psi” como um campo formado pelos elementos estranhos e insubordináveis à racionalidade epistêmica ("logia"); como um campo constitutivo do Homem em seu movimento de recorrência à epistemologia, levando em conta esse movimento como um mecanismo, ainda, de diferenciação entre as psicologias; e, por fim, como um campo que, em sua posterior diferenciação em relação à epistemologia, abriga uma condição de estranhamento entre sua dimensão teórica e epistemológica e sua dimensão prática e profissional.

\section{A diferença constitutiva do campo psi}

No prefácio à obra $A$ invenção do psicológico (2007), não por acaso publicado na coleção "Linhas de Fuga", Suely Rolnik reconhece, em seu autor, a elaboração de um triplo movimento em direção à constituição do campo "psi". O primeiro faria referência ao "isolamento atmosférico do acontecimento" (Figueiredo, 2007, p. 16), ou à expulsão da diferença em relação ao campo daquilo que pode ser dito e pensável sob o signo do princípio da identidade. Esse movimento seria um dos lados da moeda que tem, em sua outra face, a estabilização e territorialização do que Figueiredo (1996, 2002 e 2007), Freire (2002) e Safatle (2009) entenderam como o modo de subjetivação próprio da Modernidade, cuja encarnação é dada pela figura do sujeito autônomo, autocoerente, autotransparente e unitário. O correlato desse ideal de subjetivação moderno é, portanto, a epistemologia como imagem policialesca do pensamento, como tentativa de sujeitar a diferença, o movimento, o devir e a multiplicidade do caos à forma abstrata, esvaziada e transcendente da lógica, da identidade, da verdade e, ou, da validade formal. Esse passo, 
iniciado por Parmênides em sua formulação do princípio da identidade (o ser é, o não ser não é), teve sua continuidade em Platão, na divisão hierárquica entre mundo sensível e mundo inteligível, e em Kant (1996), a partir do deslocamento da atividade filosófica do conhecimento acerca das coisas para o conhecimento acerca do conhecimento das coisas, fazendo da Filosofia uma atividade perpetuamente reflexiva que começa e termina no exato ponto em que a relação de imanência entre pensamento e vida é desfeita, no momento em que o pensamento (para pensar) precisa abstrair-se da realidade. Esse (anti) movimento parece bem explicitado por Nietzsche (2008), em "A Filosofia na era trágica dos gregos", quando discorre acerca da realocação do lugar verdade, como uma tendência iniciada pela filosofia de Parmênides:

Toda aquela multiplicidade e diversidade de cores do mundo empiricamente conhecido, a mudança de suas qualidades, a ordenação de seus altos e baixos, foram, pois, impiedosamente desprezadas como uma mera aparência e ilusão; daqui nada se aprende, de sorte que todo esforço despendido com tal mundo enganador, frívolo do começo ao fim e como que fraudado pelos sentidos, é desperdiçado. [...] A verdade deve habitar, agora, apenas nas mais pálidas e abstratas generalidades, nos estojos vazios das mais indeterminadas palavras, como num abrigo feito de teia de aranha; e, junto a tal "verdade", senta-se então o filósofo, enredado em fórmulas e tão esvaído em sangue quanto uma abstração (Nietzsche, 2008, p. 84-85).

Por essa via, a atividade do pensamento só pode dar-se como atividade desvinculada da realidade, como uma não atividade, como um ato irreal, como um não ato, como uma não realidade, ao passo em que a realidade (re) aparece esvaziada, empobrecida, mortificada e transformada em algo carente de pulsação, de mudança, de potencialidade e de vida (em uma expressão: em um "beco sem saída", em uma "fatalidade"). Segundo Gadelha (2011), esse é precisamente o diagnóstico feito por Nietzsche e Deleuze em relação aos rumos tomados pela Filosofia ocidental, sob a influência parmenidiana e platônica: uma dificuldade para pensar a diferença, o movimento e o acontecimento numa relação de imanência entre pensamento e vida, sem a mediação de uma transcendência dada pelo princípio formal de identidade (cujo ideal de transparência reaparece nas entificações "Deus", "sujeito" ou "linguagem", para seguirmos o fio condutor da filosofia medieval à contemporânea). Essa dificuldade tem por correlato a codificação aristotélica da diferença sob o signo da identidade; de modo que a diferença só é possível como diferença entre duas identidades previamente constituidas, portanto como algo derivado da identidade e que lhe deve um pedágio sempre que quiser travar uma re(a) 
lação entre uma coisa e outra. Isso porque a diferença aqui referida não diz respeito a um modo de relação entre duas identidades previamente existentes, mas sim à "[...] origem do pensar, a profunda rachadura do Eu que só o leva a pensar pensando sua própria paixão" (Deleuze, 1988, p. 420). Isso parece bem explicitado por Silva:

Para isso seria preciso considerar a diferença não como resultado de um processo, mas como o processo mesmo pelo qual tanto a identidade quanto a diferença (compreendida, aqui, como resultado) são produzidas. $\mathrm{Na}$ origem estaria a diferença compreendida, agora, como ato ou processo de diferenciação (Silva, 2000, p. 76, grifos do autor).

Todavia, o processo de consolidação do ideal epistemológico moderno, conforme implica também um ideal de subjetivação, pode ser pensado como uma forma de captura ou "traição" da diferença, tal como Deleuze (1988) referiu em sua obra "Diferença e repetição". Segundo o filósofo, há quatro formas de ilusão transcendental que reabsorvem a diferença na representação, a saber: a identidade do conceito, a oposição do predicado, a analogia do juízo e a semelhança da percepção. Assim, a representação implicaria um determinado modo de domar a diferença, já que "parece que ela [a diferença] só se torna pensável quando domada" (Deleuze, 1988, p. 415). Temos aí uma percepção mais clara do segundo movimento apontado por Figueiredo (2007), a saber: a instituição do ideário epistemológico, identitário e normativo moderno, e seu correlato em termos de produção de um ideal de sujeito. Eis, portanto, o lugar da epistemologia em sua coincidência com o lugar da representação: o lugar em que a diferença é (dis)pensável.

Será, contudo, a partir da falência, da impossibilidade e do fracasso de constituição desse ideal moderno de subjetivação correlato à imagem epistemológica do pensamento, que nasce (como um terceiro movimento) o campo "psi". É exatamente esse o campo em que, na obra "Matrizes do pensamento psicológico" (Figueiredo, 2002), Figueiredo identifica com o campo da subjetividade empírica, agenciado em grande medida pelo signo "psi": tudo o que, de um sujeito ou em um sujeito pode levá-lo ao erro, ao engano, ao esquecimento, à falha, à falta; tudo o que é atravessado pelos preconceitos, pelos hábitos, pelas contingências, pelos impulsos e pelas paixões, conforme estas podem falsear a verdade; tudo o que remete à ilusão, ao irreal, ao delírio, à loucura e à extravagância, sempre possíveis quando a percepção e a interpretação colocam-se como mediações necessárias entre o conhecimento verdadeiro e o mundo; em síntese, tudo aquilo que faz 
coincidir, ao mesmo tempo, a emergência de um sujeito com a necessidade de neutralização de tudo aquilo que caracteriza a atividade específica de algo como um sujeito.

O sujeito empírico é concebido assim como fator de erro e de ilusão. Na linguagem coloquial, a atribuição de caráter subjetivo a um argumento o desqualifica diante da lógica ou diante dos fatos. A produção e a validação do conhecimento é, em última instância, o incremento do domínio técnico sobre a natureza, pressupondo a fiscalização, o autocontrole e a autocorreção do sujeito, dão origem às preocupações epistemológicas [...] e, em decorrência, a um projeto de psicologia como ciência natural do subjetivo (Figueiredo, 2002, p. 18-19, grifos nossos).

Tendo em vista o movimento acima esboçado, poderemos chegar a um resumo deste com base na seguinte fórmula: a Psicologia consiste na sintese cujo principal movimento é a tentativa de eliminar a diferença entre "psi" e "logia". Isso porta uma grande significação, inclusive no que diz respeito a uma percepção sobre possíveis reencaminhamentos para formulaçôes curriculares referentes aos cursos de Psicologia. Ora, conforme entendemos como constitutivo do campo "psi" (e, portanto, também do campo "psico-lógico") precisamente o espaço da diferença, em seus escapes estéticos, políticos e teóricos em relação à imagem de pensamento ligada à epistemologia moderna, isso quer dizer que tais referências não podem mais ser pensadas como de fora da Psicologia. A Psicologia é, portanto, em sua própria constituição, e não mediante uma leitura posterior de intelectuais que queiram transversalizá-las por outros campos, um saber multidisciplinar, interdisciplinar, transdisciplinar e indisciplinado (Figueiredo, 1996). Assim, os elementos que se situam de fora, ou em exterioridade em relação ao que usualmente chamamos de "Psicologia" (a saber: literatura, arte, poesia, cinema; mas também Filosofia, Sociologia, Antropologia, Ciência Política) foram, aos poucos, situando o lugar da diferença como o desvio da verdade, do conhecimento e da identidade, desvio este cujo impulso foi expulso para pulsar no campo "psi”.

\section{O Homem, a Psico-logia e suas diferenças}

Em seu texto "A Psicologia de 1850 a 1950", Michel Foucault (2010) chama atenção para um curioso movimento realizado pela Psicologia, aqui chamado de movimento de segunda ordem, pelo qual esta realiza um esforço para dominar as contradições que lhes são próprias. De que "contradições" o autor nos fala? Ora, se a Psicologia dos distúrbios, dos conflitos, das patologias e das anormalidades constitui instância de saber-poder para o encaminhamento 
de uma Psicologia do normal, Foucault (2010) dirá que isso se deve a uma tentativa posterior da Psicologia, não coincidente com a sua atitude inicial. Atenhamo-nos às palavras do filósofo e cientista político francês:

A psicologia, em contrapartida, nasce nesse ponto em que a prática do homem constitui sua própria contradição: a psicologia do desenvolvimento nasceu como uma reflexão sobre as interrupções do desenvolvimento; a psicologia da adaptação, como uma análise dos fenômenos da inadaptação; a da memória, da consciência, do sentimento surgiu, primeiro, como uma psicologia do esquecimento, do inconsciente e das perturbações afetivas. Sem forçar uma exatidão, pode-se dizer que a Psicologia contemporânea é, em sua origem, uma análise do anormal, do patológico, do conflituoso, uma reflexão sobre as contradições do homem consigo mesmo. E se ela se transformou em uma psicologia do normal, do adaptativo, do organizado é de um segundo modo, como que por um esforço para dominar estas contradiçōes (Foucault, 2010, p.134-135, grifos nossos).

Nesse contexto, devemos entender que as "contradições do homem consigo mesmo" referem-se ao espaço de constituição do Homem, duplicado na dimensão empírica e na dimensão transcendental, tal como explicitado por Foucault (2007), em "As palavras e as coisas". "O Homem" constituirá, portanto, um movimento de transcendência que intenta romper com o plano da imanência (Deleuze \& Guattari, 1996) e, desse modo, erige-se como ideal regulatório dos homens concretos e empíricos que acontecem no mundo. Contudo, enquanto essa invenção recente ("O Homem") não se dissolve como um rosto de areia na borda do mar (Foucault, 2007), importa-nos trazê-lo para o plano da imanência e perceber como esses efeitos são agenciados pelos saberes e práticas psi. O primeiro passo para interrogar-se pela genealogia do homem será, então, perceber os entraves para que a própria questão seja colocada, como bem aponta Derrida (1991, p. 154-155): "A história do conceito de homem nunca é interrogada. Tudo se passa como se o signo 'homem' não tivesse qualquer origem, qualquer limite histórico, cultural, linguístico".

Nesse sentido, para pensarmos em termos de efeitos do ideal de Homem no plano de imanência, poderemos ter uma boa pista a partir do que nos escreve Safatle (2009, p. 206): "O homem como entificação de um certo regime de pensar é, além de um projeto teológico-político, um projeto eminentemente terapêutico"( grifos do autor). O sentido de "terapêutico" dado por Safatle (2009) assemelha-se bastante às características do que Foucault (2010) entendeu como movimento de segunda ordem agenciado pela Psicologia 
no sentido de domar suas contradições constitutivas: "Um conjunto de procedimentos que visam impor uma certa normalidade como padrão de normatividade da vida" (Satafle, 2009, p. 206). Assim, a síntese entre "psi" e "logia" (a "Psicologia") não será meramente uma instância de saber-poder que atravessará e preencherá com seus conteúdos, seus valores, suas técnicas e suas diferentes "visões de homem" os contornos na forma "Homem"; mais do que isto, ela será uma instância privilegiada no próprio movimento de traçar os contornos dessa figura. Será precisamente isso que levará Foucault a afirmar, em entrevista concedida a Alain Badiou, em 1965, que a forma de interrogação do homem por si mesmo e sobre si mesmo assumiu foi agenciado preponderantemente por uma "forma cultural" que hoje em dia chamamos de "Psicologia" (Foucault, 1965).

Ora, mas se essa atitude posterior, esse movimento de segunda ordem, essa tentativa de domesticar e neutralizar aquilo inicialmente posto $\mathrm{em} \mathrm{seu}$ campo e para a formação de seu campo consiste num dos principais esforços de um campo que pretende cientificidade e, portanto, justificação, isso nos leva à seguinte questão: que movimentos a Psicologia teria de efetivar a fim de realizar justificadamente esse movimento de segunda ordem? Para produzir efeitos desejados, de que regimes de verdade a Psicologia teria de se valer? A argumentação trazida por Michel Bernard (1983), por Figueiredo (2002) e por Ferreira (1999) é que as psicotécnicas precedem a Psicologia e que, numa tentativa de legitimação de suas práticas (exigência do espírito laico e "crítico" do Iluminismo e da Modernidade), fez-se necessária a recorrência, a importação e a caução (cujo álibi de "fundamentação" parece funcionar muito mais como uma confissão de um pedido de socorro) da epistemologia como instância que poderia garantir a continuidade da aplicação dessas mesmas psicotécnicas.

Assim, a Psicologia não deve ser considerada (como usualmente o é por um pensamento crítico e denuncista que não consegue colocar em perspectiva o surgimento da forma "homem") meramente como uma instância de normalização, sujeição e controle dos homens; mas, antes de tudo, como uma instância de normalização, de sujeição de controle através da constituição da figura "homem". Será, portanto, para sair desse primeiro lugar em direção ao segundo que a Psicologia, ao recorrer à epistemologia, faz as psicotécnicas aparecerem como subprodutos de sua Ciência, como consequências e aplicaçóes de suas concepçóes de conhecimento de mundo e principalmente de homem travadas na sua recorrência à epistemologia. Tais psicotécnicas, descritas por Bernard (1983) em seu instigante artigo "A Psicologia", são intimamente relacionadas aos instrumentos simples de atualização do 
poder disciplinar, descritos por Foucault (1997) em "Vigiar e punir", como vigilância hierárquica, sanção normalizadora e exame. E isso na medida em que constituíram o subsolo fundamental das Ciências Humanas em relação às quais as epistemologias não pareceram exercer muita coisa além de uma função superestrutural, de adorno, de perfumaria ou "depuração especulativa" (Foucault, 1997, p. 186).

Estas ciências [Psicologia, Psiquiatria, Pedagogia] com as que nossa "humanidade" se encanta há mais de um século têm sua matriz técnica na minúcia tateante e maldosa das disciplinas. Estas são talvez, para a psicologia, a pedagogia, a psiquiatria e a criminologia, e para tantos outros estranhos conhecimentos, o que foi o terrível poder de inquérito para o saber calmo dos animais, das plantas ou da terra (Foucault, 1997, p. 186).

Todavia, faz-se necessário chamar atenção a um ponto crucial. $\mathrm{O}$ momento de recorrência à epistemologia constituirá signo maior não da unificação, mas da dispersão do campo psicológico. Em sua impactante palestra ministrada em dezembro de 1956 ao Collège de Philosophique intitulada "O que é a Psicologia?", Georges Canguilhem (1973) fala que, no campo da Psicologia, jaz uma diferença, insubordinável a qualquer projeto de unificação, entre as imagens de homem, de conhecimento e de mundo que cada uma das abordagens psicológicas forja. Se essas imagens de conhecimento, de homem e de mundo arquitetam-se no plano teórico e epistemológico como justificação das psicotécnicas, o que sustentaria a unificação das psicologias é precisamente a sua condição de instrumento da instrumentalização do homem, ou seja, a dimensão funcional e pragmática da produção de "efeitos" oriundos da aplicação de técnicas psicológicas. Muito mais agenciadas, contudo, por um empirismo tateante e heterogêneo do que pela discernível aplicação de uma ciência, a Psicologia encontra na "prática" sua razão de ser, sua identidade e sua unificação perdida nos labirintos das firulas, das querelas, das sutilezas e dos mal-entendidos que aparecem quando a epistemologia comparece. Isso porque "para uma Psicologia na qual a palavra alma faz fugir, a palavra consciência faz rir, a verdade do homem está dada pelo fato de que não há mais nenhuma ideia de homem enquanto valor diferente daquela de um instrumento" (Canguilhem, 1973, p. 23).

Desse modo, essa unificação funcional e pragmática tem como correlato o que Canguilhem (1973) entendeu como um "pacto de coexistência pacífica entre as Psicologias", mediante o qual cada perspectiva psicológica ocupa-se unicamente com o conjunto de questóes epistemológicas que gravitam em torno de uma semelhante imagem de homem, de mundo e de conhecimento. 
O agenciamento "Psico-logia" aparece, assim, num movimento de constituição que, se devidamente clareado, nada tem de paradoxal em seus mecanismos: se seu subsolo fundamental é a instrumentalização do homem, via de unificação pragmática da Psicologia, seu enfeite mais importante é a Epistemologia, meio de diferenciação teórica das Psicologias. Saindo do aparente paradoxo para uma compreensão do que está para além da doxa, e fazendo, portanto, uma metadoxa ou uma para-doxa, podemos perguntar: que formulações discursivas tidas, consideradas e supostas como verdadeiras são agenciadas para lidar com a diferença entre as psicologias? De que forma os intelectuais da área "psi", os estudantes de Psicologia e os profissionais psicólogos entendem que as psicologias se relacionam? Qual a doxa que sustenta aquilo que aparece como uma relação entre as epistemes? Assim, chegamos ao ponto que nos interessa neste segundo movimento relativo à diferença entre as formas de síntese da "Psico-logia"; e aqui dizemos diferença entre porque remetemo-nos a todo o campo dos acontecimentos, das multiplicidades e dos devires que tentam ser configurados e territorializados pelas abordagens, mas que escapam e atravessam de uma perspectiva a outra, provocando articulações, alianças e rupturas sempre estranhas ao movimento ascético da Epistemologia.

Tendo em vista tal pacto, este trabalho salienta a importância, para um melhor entendimento não somente sobre a constituição, mas também sobre o funcionamento da Psicologia, de estudos acerca dos modos como se relacionam entre si as distintas perspectivas teóricas que realizam a síntese "Psicologia"; o que, infelizmente, sabemos ser extremamente obstacularizado pelo isolacionismo diferencialista de boa parte de uma produção teórica do campo da(s) Epistemologia(s) da(s) Psicologia(s). Sob o argumento de que os posicionamentos epistemológicos das psicologias não se cruzam, mas são autocoerentes somente no interior de seus territórios, a Psicologia constitui um importante regime de verdade que faz o seu escape via epistemologia aparecer como o fundamento de sua dispersão. Assim, estudos mais atentos aos regimes de verdade que norteiam a re(a)lação entre as abordagens psicológicas seriam de extrema importância, tanto porque nos permitiriam uma cartografia sobre os modos de encaminhar a diferença entre as Psicologias, como porque entendemos que há outra fundamental diferença, a saber: a diferença entre o modo como as psicologias se relacionam no âmbito epistemológico (algo semelhante a um pluralismo pacífico, de respeito e desinteresse pela diferença) e o modo como se relacionam no âmbito da prática profissional, no qual percebemos, de forma mais nítida, os enfrentamentos e as disputas de poder. Quanto à diferença entre as psicologias, entendida como o conjunto de acontecimentos, de devires, de forças e de valores implícitos que estão 
entre as psicologias sem que suas epistemologias percebam muito bem, mas entendida também como movimentos de rupturas e de territorializações em "abordagens", faz-se importante a consulta do texto "A gestação do espaço psicológico no século XIX: liberalismo, romantismo e práticas disciplinares", de Figueiredo (2007).

Este trabalho, contudo, não pretende apontar especificamente quais são essas diferenças e nem investigar detalhadamente o modo como se propagam, dentro do campo da Psicologia, de uma abordagem a outra (o que poderá ser realizado como uma continuação da proposta deste estudo); mas pretende procurar explicitar os contextos, as consequências e, com isso, as contingências das atuais formas de fragmentação do campo psicológico, conforme essa fragmentação diz de uma resposta à tensão entre o espaço da diferença e o espaço da epistemologia. Nesse contexto, as obras de Luís Cláudio Figueiredo, bem como o campo das filosofias da diferença e os autores referidos no decorrer deste trabalho nos são de valia precisamente por fazerem referência aos pontos por onde passam os agenciamentos valorativos estéticos, éticos e políticos que as epistemologias das psicologias tentam neutralizar e, ou, obscurecer. Isso nos levará no sentido de uma cultura pós-epistemológica em Psicologia (Figueiredo, 1996) e, para isso, um estudo teórico e "epistemológico" (sobre formas de conceber a relação sujeito-objeto, critérios de concepção de um conhecimento válido, relações entre metodologia, ciência e epistemologia, formas de lidar com a fundamentação e com a produção de conhecimentos novos, etc.) será uma atividade fundamental para nosso propósito. Dessa forma, poderemos fazer com a epistemologia movimento semelhante àquele feito por Wittgenstein (2001), em seu "Tractatus logico-philosophicus", com a Filosofia, a saber: "Após ter escalado através delas - por elas - para além delas [...] deve-se, por assim dizer, jogar fora a escada após ter subido por ela" (Wittgenstein, 2001, p. 281).

\section{A diferença entre Psicologia e Epistemologia}

Um terceiro movimento que devemos contemplar, a partir da perspectiva que situamos neste trabalho, dirá respeito propriamente ao estabelecimento de uma diferença entre Psicologia e Epistemologia. A significação desses termos, contudo, sofrerá uma série de modificações e de deslocamentos, gerando vários mal-entendidos, precisamente porque o campo em que essa nova significação incide retorna novamente ao lugar de onde proveio: das técnicas. Um dos sinais dessa modificação é precisamente o fato de que a oposição entre técnicas e justificaçôes, que outrora impelia a Psicologia em 
mover-se das técnicas em direção às justificações, cede lugar a uma nova oposição: a oposição entre teoria e prática que, ao contrário da anterior, tende movimentar a Psicologia no sentido da teoria para a prática. Em semelhança aos argumentos esboçados por Figueiredo (1996; 2002; 2007) e Ferreira (1999), esse movimento imanente à própria Psicologia a leva a uma distância em relação à epistemologia, e isso porque esse campo não lhe é afim sob dois aspectos fundamentais: nem em sua fundação pela via da diferença que escapa à imagem do pensamento e da subjetivação modernos, nem em sua tentativa de estabelecer uma integração necessária a toda prática que pretende unidade, corporativismo e um somatório de forças para fazer funcionar seu(s) regime(s) de verdade contra outros.

Um dos signos mais claros desse deslocamento de significação é apontado precisamente por Canguilhem (1973, p. 25): “A questão 'Que é a psicologia?', na medida em que se interdita a psicologia de procurar sua resposta, torna-se: 'Onde querem chegar os psicólogos fazendo o que fazem? Em nome de quem se declaram psicólogos?””. Assim, a questão "o que é a Psicologia?", ao passar por uma grade de escuta e de codificação própria aos psicólogos, chega-lhes como "o que faz a Psicologia?", "o que a Psicologia realmente faz?", ou mesmo "o que a Psicologia faz na prática?". Portanto o incômodo mediante a questão "O que é a Psicologia?" parece incidir e ter sua razão de ser no contexto em que a Psicologia é convocada a fazer alguma coisa, e fazer alguma coisa como algo diferente de uma Filosofia. Se a pergunta por sua definição, contudo, de modo algum constrange o filósofo, mas antes retroalimenta seu saber, a razão pela qual essa mesma pergunta paralisa o psicólogo poderá ser buscada mediante a diferença entre a Epistemologia (como a disciplina filosófica disciplinadora do pensamento humano) e a Psicologia.

Contudo, esse movimento para a prática da Psicologia, de uma forma irônica, finda por conferir à epistemologia (cujas funções para o pensamento sempre se assemelharam ao policiamento e ao julgamento) um ar filosófico, libertário, crítico e questionador, aparentemente bastante afeito à diferença, ao devir e às multiplicidades. O epistemólogo da Psicologia aparece, então, para o psicólogo atuante em uma empresa, uma escola, um hospital ou um centro de referência como aquele que exercita o pensamento, como aquele que é capaz de criticar a Psicologia, ou como aquele que é capaz de entender melhor a Psicologia para além da prática. Mas também, por outra via, como aquele que somente pensa, que somente critica, mas desconhece a realidade e não consegue operar, agir e atuar com aquilo que pensa; em última instância e em casos mais drásticos: como aquele que nada propóe. Se isso, todavia, diz de uma representação da epistemologia no campo da Psicologia, será a 
Psicologia quem mais se mobilizará no sentido de "resolver os problemas da prática", em "solucionar as demandas", em "agir na própria realidade", o que faz funcionar uma série de processos de territorialização, organização, normalização, previsão, controle e estabilidade (tudo o que uma investigação teórica, epistemológica e crítica poderia fazer desabar mediante o primeiro questionamento). Assim, no campo da prática, a Psicologia se sustenta na diferença em relação à epistemologia; e, pela mesma via, a Psicologia se desgarra da epistemologia para funcionar seus efeitos nesse campo da prática. A prática psicológica, assim, procura, o máximo possível, esquivar-se das interrogações, das questôes e dos julgamentos da epistemologia da Psicologia, que poderá sempre ameaçar a validade daquilo que a prática julga "realmente" fazer.

Aqui assistimos a um dos tristes efeitos da cisão e da perda da imanência entre pensamento e vida, esboçados no primeiro tópico deste trabalho: o pensamento é visto como uma abstração sem matéria, sem atividade e sem realidade; e a vida, por seu turno, é vista como a realidade nua e crua, sem potencialidades, sem vibrações, sem cores e sem intempestividades. Conforme referido por Gadelha (2011), tal perda da imanência entre pensamento e vida constitui precisamente um dos principais pontos de denúncia das filosofias que se afiliam à diferença, ao devir, à multiplicidade e ao acontecimento. Esse movimento de bifurcação e paralisação do devir em uma epistemologia abstrata e jurídica e em uma realidade prática empobrecida e fatalisticamente determinada, típico do campo da Psicologia, parece constituir numa das possíveis formas de rompimento da imanência entre pensamento e vida, como podemos ver nas palavras de Deleuze:

Em vez da unidade de uma vida activa e de um pensamento afirmativo, vemos o pensamento dar-se por tarefa julgar a vida, de lhe opor valores pretensamente superiores, de a medir com esses valores e de a limitar, a condenar. Ao mesmo tempo que o pensamento se torna assim negativo, vemos a vida depreciar-se, deixar de ser ativa, reduzir-se às suas formas mais fracas, a formas doentias só compatíveis com os valores ditos superiores. Triunfo da "reacção" sobre a vida activa e da negação sobre o pensamento afirmativo (Deleuze, 1985, p. 18-19, grifos do autor).

É precisamente essa perda da imanência que, no campo da Psicologia, causanos a sensação de que a teoria constitui ferramenta inoperante e de que a prática, por seu turno, lida com entraves, empecilhos e dificuldades incontornáveis e que constituem uma fatalidade para o psicólogo, que nada pode fazer diante disso. Com isso, o campo da Psicologia é facilmente convocado a adentrar no reino das cisões: teoria x prática, mercado de trabalho $\mathrm{x}$ atividade acadêmica, 
crítica x proposição, epistemologia $\mathrm{x}$ aplicação, universidade (sempre referida por seus "muros") x "mundo lá fora". E, em tentativa de contornar, suturar, mascarar e esconder essas cisões, temos uma propagação de enunciados que atuam sob a forma de uma retórica interacionista muito pouco convincente caso examinada com um pouco mais de atenção. Esses enunciados buscam precisamente dizer que "teoria e prática são uma coisa só", que são "instâncias complementares, indissociáveis, que devem estar em harmonia e caminhar de mãos dadas". Caso o leitor tenha acompanhado o fio argumentativo deste trabalho, poderá perceber o quão esses enunciados são tributários de um movimento de redirecionamento da Psicologia à sua prática, de dissociação da Psicologia da epistemologia e, principalmente, de denegação dessa separação.

Em seu livro "Revisitando as psicologias", Figueiredo (1996) assumirá um posicionamento semelhante quando pensará nas formas de suturar, de mascarar e de contornar a angústia causada pela fragmentação do campo psicológico. Se a unificação é constantemente negada no campo epistemológico e, portanto, dificilmente encorajada de ser assumida no campo prático, temos o ecletismo e o dogmatismo como formas de aliviar a tensão causada pela diferença entre as psicologias (tema do segundo item deste trabalho). O ecletismo, por um lado, nega a tensão e a irredutibilidade dessa diferença precisamente porque julga ser possível que cada teoria seja aplicada e válida a depender da demanda e da situação. Seu slogan poderia ser traduzido como "todas as psicologias podem unir esforços para enfrentar os desafios da prática”, e sua atitude permanece refém da doxa, daquilo que Deleuze e Guattari (2010) chamaram de lógica da comunicação, de propagação de clichês e palavras de ordem, quando estagnam e não problematizam o significado de termos como "prática", "bem-comum", "comunidade" e quando supõem serem óbvios, evidentes e consensuais os valores, as finalidades e o telos da prática psicológica. Se o ecletismo constitui regime de verdade dificilmente aceito no campo teórico-epistemológico da Psicologia, porém facilmente, se não aceito e assumido, pelo menos exercido em demasia no campo da prática, o dogmatismo constituirá um regime de verdade predominante no campo universitário, porém dificilmente assumido até suas últimas consequências no campo da prática. O dogmatismo universitário é, contudo, no campo da Psicologia, não um dogmatismo com pretensões de totalização, mas, de acordo com as próprias indicações já dadas por Canguilhem (1973), um dogmatismo pluralista e internalista. Trata-se de um dogmatismo que reconhece a existência possível e perfeitamente convivível de outras perspectivas teóricas em Psicologia (muito embora constantemente se volte criticamente quando a questão "desce" à prática) e que entende que cada perspectiva teórica só 
pode ser compreendida, criticada e avaliada de dentro. Assim, enquanto que se constituem como doxas, o ecletismo e o dogmatismo se arquitetam como ferramentas para compreender a relação entre as psicologias na tentativa de verter e converter à pacificação a diferença disruptiva, inatual, extemporânea e intempestiva que circula entre as Psicologias.

É preciso perceber o que estas duas defesas contra a angústia têm em comum: elas bloqueiam o acesso à experiência [...] só há experiência onde há diferença e onde novas diferenças são engendradas. Ora, tanto o dogmático não se dispõe a nada disso, como o eclético procura manter-se fundamentalmente o mesmo, encobrindo esta imobilidade e esta mesmice impermeável com a fantasia da variedade e da liberdade (Figueiredo, 1996, p. 18-20, grifo do autor).

\section{Considerações finais}

Este trabalho pretendeu, fundamentalmente, apontar para novas vias de análise acerca da constituição do campo da Psicologia, tendo em vista algumas diferenças que se interpõem em seu conflituoso (des)encontro com a epistemologia. Ainda que nosso objetivo não permitisse uma análise mais pormenorizada dos entraves, desencontros e mal-entendidos que emergem no contexto específico da prática profissional, esperamos que as considerações aqui tecidas possam lançar luzes para o reencaminhamento de algumas questôes que gravitam sobre esse terreno. Assim, a diferença entre a Psicologia na e da universidade e a Psicologia no e do mercado de trabalho deve ser pensada não somente em razão do contexto sociopolítico contemporâneo, mas também das próprias características da constituição histórica do campo da Psicologia. Se essa diferença, contudo, não é um reflexo imediatamente perceptível da diferença entre o campo "psi” e o campo da "logia"; se esta não é, também, uma consequência direta do tipo de enfrentamento gerado pela diferença entre as psicologias; e se, por fim, esta ainda não constitui mero avatar da diferença entre Psicologia e epistemologia, nossa argumentação procurou lançar luzes sobre os (des)caminhos que levam à constituição de um campo que, na tentativa de colocar-se para além da doxa, apresenta uma série de cisões, desencontros, vácuos e mal-entendidos não facilmente e imediatamente articuláveis entre si, e nem solucionáveis. Nesses (des) caminhos, contudo, esperamos que tais diferenças, descritas mediante os três tópicos anteriores, não sejam vistas como mero acaso, mera arbitrariedade e nem como algo natural, óbvio e inevitável para o campo da Psicologia. Esperamos, ao contrário, que esse estudo tenha conseguido lançar algumas 
luzes sobre a re(a)lação que interliga esses três movimentos da diferença na constituição da Psicologia diante da epistemologia. Isso para que essa re(a) lação entre Psicologia, diferença e epistemologia constitua, para nós, não só um campo de maior clareza, mas um campo onde se faça possível um refazer que não seja refém dos fatalismos e que possa agenciar resistências no campo teórico-político da Psicologia.

\section{Referências}

Bernard, M. (1983). A psicologia. In Chatelêt, F. (Org.). História da filosofia. (M. J. de Almeida, trad., Ideias, doutrinas, Vol. 7, pp. 19-88). Lisboa: Dom Quixote. (Texto original publicado em 1973).

Canguilhem, G. (1973). O que é a psicologia? (O. F. Gabbi, trad.). Impulso, 26 (11), 11-26. (Texto original publicado em 1958).

Deleuze, G. (1985). Nietzsche. (A. Campos, trad.). Lisboa: Edições 70. (Texto original publicado em 1965).

Deleuze, G. (1988). Diferença e repetição. (L. Orlandi e R. Machado, trad.). Rio de Janeiro: Graal. (Texto original publicado em 1968).

Deleuze, G. \& Guattari, F. (1996). Mil platôs: capitalismo e esquizofrenia. (A. Guerra e S. P. Costa, trad.). São Paulo: Editora 34. (Texto original publicado em 1980).

Deleuze, G. \& Guattari, F. (2010). O que é a filosofia? (B. Prado Jr. e A. Muñoz, trad.). São Paulo: Editora 34. (Texto original publicado em 1991).

Derrida, J. (1991). Margens da filosofia. (J. T. Costa e A. M. Magalhães, trad.). Campinas: Papirus. (Texto original publicado em 1972).

Ferreira, A. (1999). A diferença que nos une: um estudo sobre as condiçôes de surgimento do saber psicológico em sua dispersão. Tese de Doutorado em Psicologia, Programa de Estudos Pós-graduados em Psicologia Clínica, Pontifícia Universidade Católica de São Paulo, São Paulo.

Figueiredo, L. (1996). Revisitando as psicologias. Petrópolis: Vozes.

Figueiredo, L. (2002). Matrizes do pensamento psicológico. Petrópolis: Vozes. 
Figueiredo, L. (2007). A invenção do psicológico: quatro séculos de subjetivação: 1500-1900. São Paulo: Escuta.

Foucault, M. (1965). Filosofía e psicología: psicoanálisis: depoimento a Alain Bardiou. Disponível em: http://www.youtube.com/watch?v=1e8Rynio0B8.

Foucault, M. (1997). Vigiar e punir: nascimento da prisão. (R. Ramalhete, trad.). Petrópolis: Vozes. (Texto original publicado em 1975).

Foucault, M. (2007). As palavras e as coisas. (S. T. Muchail, trad.). São Paulo: Martins Fontes. (Texto original publicado em 1966)

Foucault, M. (2010) A psicologia de 1850 a 1950. In M. B. da Motta (Org.). Ditos e escritos. (V. L. Ribeiro, trad., Vol. 1, pp. 133-151). Rio de Janeiro: Forense Universitária. (Texto original publicado em 1957).

Freire, C. (2002). O lugar do Outro na modernidade tardia. São Paulo: Annablume.

Gadelha, S. (2012). Sobre o esvaziamento da materialidade do Ser: entre Deleuze e a leitura nietzscheana de Parmênides. In Castro, R., Costa, G. \& Carvalho, D. (Orgs.). Nietzsche Schopenhauer: Schopenhauer, Nietzsche e a antiguidade. (pp. 175-196). Fortaleza: Ed. UECE.

Kant, Immanuel. (1996). Crítica da razão pura. (V. Rohden e U. B. Moosburger, trad.). São Paulo: Nova Cultural. (Texto original publicado em 1781).

Nietzsche, F. (2008). A filosofia na era trágica dos gregos. (F. R. Barros, trad.). São Paulo: Hedra. (Texto original publicado em 1873).

Safatle, W. (2009). Sobre a potência política do inumano. In A. Novaes (Org.). A condição humana: as aventuras do homem em tempos de mutação. (pp. 199-220). Rio de Janeiro: Agir.

Silva, T. (2000). A produção social da identidade e da diferença. In T. T. Silva, S. Hall, K. Woodward (Orgs.). Identidade e diferença. (pp. 73-102). Petrópolis: Vozes.

Wittgenstein, L. (2001). Tractatus logico-philosophicus. (L. H. Santos, trad.). São Paulo: Edusp. (Texto original publicado em 1921). 